\title{
Review \\ Revisit the cellular transmission and emerging techniques in proteinopathies
}

\author{
Jinwen Jiang', Yu Liu', Qihui $\mathrm{Wu}^{1}{ }^{1, *}$
}

1 Translational Research Institute of Brain and Brain-Like Intelligence, Shanghai Fourth People's Hospital affiliated to Tongji University School of Medicine, Shanghai, China

* Correspondence: qihuiwu@tongji.edu.cn

Abstract: Alzheimer's and Parkinson's diseases (AD and PD) are amongst top of the prevalent neurodegenerative disease. One-third of $\mathrm{PD}$ patients are diagnosed with dementia, a pre-symptom of $\mathrm{AD}$, but the underlying mechanism is elusive. Amyloid beta $(\mathrm{A} \beta)$ and $\alpha$-synuclein are two of the most investigated proteins, whose pathological aggregation and spreading are crucial to the pathogenesis of $\mathrm{AD}$ and $\mathrm{PD}$, respectively. Transcriptomic studies of the mammalian central nervous system shed light on gene expression profiles at molecular levels, regarding the complexity of neuronal morphologies and electrophysiological inputs/outputs. In the last decade, the booming of the single-cell RNA sequencing technique helped to understand gene expression patterns, alternative splicing, novel transcripts, and signal pathways in the nervous system at single-cell levels, providing insight for molecular taxonomy and mechanistic targets of the degenerative nervous system. Here, we re-visited the cell-cell transmission mechanisms of $A \beta$ and $\alpha$-synuclein in mediating disease propagation, and summarized recent single-cell transcriptome sequencing from different perspectives and discussed its understanding of neurodegenerative diseases.

Keywords: Alzheimer's disease; Parkinson's disease; A $\beta$ cascade hypothesis; $\alpha$-synuclein aggregation and spreading; transcriptomics of nervous system

\section{Introduction}

The deposition of $\beta$-sheet containing amyloid aggregates featured many neurodegenerative diseases, such as amyloid- $\beta(\mathrm{A} \beta)$ and tau in Alzheimer's disease (AD), $\alpha$-synuclein in Parkinson's disease (PD), and TAR DNA-binding protein (TDP) 43 in amyotrophic lateral sclerosis (ALS), which causes inflammation, neuronal dysfunction, movement and cognition defects. These infectious amyloidogenic 'seeds' are self-template dependent replication, transcellular propagation, and transmissible of neuropathology between distinct brain regions. This review discussed the contribution of transcellular propagation of $\mathrm{A} \beta$ oligomers/fibrils in $\mathrm{AD}$ and $\alpha$-synuclein ( $\alpha$ Syn) aggregates in PD, in which $30-40 \%$ of PD has been diagnosed with dementia, an early symptom of AD. It also discussed the recent advance of RNA sequencing techniques in the application of neurodegenerative diseases. Unlike traditional biochemistry and molecular biology, single-cell RNA sequencing (scRNA-seq) helps to understand multiple gene expression patterns and signal pathways in the nervous system at the single-cell level, aiming to impact the development of new diagnostic and therapeutic strategies in the degenerative nervous system.

\section{Results}

2.1. The pathogenesis of $\mathrm{AD}$-related $\beta$-amyloid cascade hypothesis

$\mathrm{AD}$ is the most common degenerative disease of the nervous system that occurs in the elderly. Its clinical manifestations are mainly characterized by progressive memory decline and later comprehensive cognitive dysfunction. AD patients have a long course of the disease, gradually lose the ability to live, and eventually die of complications due to the inability to take care of themselves [1]. The two primary cardinal lesions associated 
with $\mathrm{AD}$ are the neurofibrillary tangle and the senile plaque [2]. The neurofibrillary tangle consists of abnormal accumulations of phosphorylated tau within the perikaryal cytoplasm of specific neurons. The senile plaque consists of a central core of beta-amyloid, a 4-kD peptide, surrounded by abnormally configured neuronal processes or neurites. Other neuropathological lesions are encountered in cases of $\mathrm{AD}$, but the disease is defined and recognized by these two cardinal lesions. Other lesions include poorly understood changes such as granulovacuolar degeneration and eosinophilic rodlike bodies (Hirano bodies). The loss of synaptic components is a change that has a significant impact on cognitive function and represents another crucial morphological alteration. It is essential to recognize that distinguishing between $\mathrm{AD}$, especially in its early stages, and normal aging may be complicated, particularly if one examines the brains of patients who died at an advanced old age. It is also noted that instances of pure forms of AD, in the absence of other coexistent brain disease processes, such as infarctions or PD-related lesions, are relatively uncommon.

The gross pathological manifestation of AD is brain atrophy [3]. The etiology and pathogenesis of AD are complex, and there is currently no effective prediction method. Previous clinical and basic research evidence around $\mathrm{A} \beta$ pointed out that it played a vital role in the course of $\mathrm{AD}$ [4]. However, none of the drugs targeting $\mathrm{A} \beta$ passed clinical trials, suggesting the complexity of the onset of AD. The A $\beta$ cascade hypothesis has also been challenged. Re-recognizing the role of the $A \beta$ cascade hypothesis in the pathogenesis of $A D$ and exploring possible new ways of AD will be the direction of future AD research. Here, we summarized the $\mathrm{A} \beta$ cascade hypothesis and related AD pathology, pathophysiological process, and treatment research progress.

At present, the pathogenesis and etiology of $\mathrm{AD}$ are still unclear. It believes that $\mathrm{A} \beta$ is a polypeptide obtained by continuous hydrolysis of amyloid precursor protein (APP) under the action of $\beta$ and $\gamma$ secretases. The matrix precipitates and accumulates. Among them, the soluble aggregates of $A \beta$ are considered the main form of neurotoxicity and eventually cause cognitive dysfunction [5] and play a crucial pathological role in AD. The deposition of $A \beta$ aggregates leads to the formation of a large number of SP in the brain.

A $\beta$ directly acts on neurons and produces toxic effects. Moreover, it also activates microglia and astrocytes in the brain to produce cytokines, induce inflammatory response, and trigger cell death eventually. Within the chronic inflammation of the nervous system, activated microglia can engulf synapses in the early stage of AD [6]. In addition, the hyperphosphorylation of the microtubule-associated protein Tau in neurons can also be downstream of the excessive production and aggregation of $A \beta$, which in turn leads to neuronal degeneration in the brain, leading to AD-related dementia [7].

Misfolding and aggregation of $\mathrm{A} \beta$ in the brain is a critical step in the course of AD [8]. A $\beta$ can exist in the brain in three soluble forms, including monomeric $A \beta, A \beta$ oligomers, and fibrillar [4]. Fibrillar $A \beta$, also known as $A \beta$ fibrils, can act as a pro-oxidant, induce protein oxidation, and change the activity of oxidation-sensitive enzymes [9]. The oligomerized $\mathrm{A} \beta$ can be embedded in the bilayer of the neuronal membrane to increase the membrane's permeability, leading to an increase in reactive oxygen species in the cell, triggering mitochondrial dysfunction, and inducing lipid peroxidation. Therefore, in neurodegenerative diseases related to $\mathrm{A} \beta$, the change of cell membrane permeability is a common phenomenon. In addition, more and more evidence has suggested that A $\beta$ oligomers are the real "culprit" of AD in recent years. After Walsh et al. [10] reported in 2002 that A $\beta$ oligomers had a damaging effect on rats' long-term potentiation (LTP), scientists gradually revealed that $A \beta$ aggregation has deleterious effects on neuronal structure and cognition [11-13]. In 2008, Shankar et al. [14] extracted A $\beta$ oligomers from the cerebral cortex of AD patients, added them to the hippocampal slice incubation solution, or injected them into the rat lateral ventricle, which caused the attenuation of hippocampal LTP and enhancement of long-term depression (LTD), decreased the hippocampal dendritic spine density and the 
decline of learning and memory ability in normal rats. This work has consolidated the critical contribution of $\mathrm{A} \beta$ oligomers in the pathogenesis of $\mathrm{AD}$ from a pre-clinical perspective.

In the normal brain, $A \beta$ is not useless. There is experimental evidence that $A \beta$ monomer has neurotrophic effects [15]. When the brain is in a physiological state, the production and degradation of $\mathrm{A} \beta$ is a dynamic equilibrium process. If too much production or degradation slows down, $A \beta$ will accumulate progressively and become an insoluble form of dense plaque, that is, SP. The removal of SP may increase the content of A $\beta$ oligomers and accelerate neuronal degeneration [16-17].

After the A $\beta$ in the brain is produced by APP hydrolysis and metabolism, it can be degraded in the brain by glial cells and some enzymes, such as NEP and insulin degradation enzyme (IDE), and it can also be transported through the blood. $A \beta$ is produced from the cell and secreted into the intercellular fluid, enters the cerebrospinal fluid through the brain-cerebrospinal fluid barrier, and transports from the cerebrospinal fluid to the blood and lymphatic system through the blood-brain barrier (BBB) and arachnoid villi or perivascular, where the $A \beta$ is cleared but also accumulated within the whole body. The lymphatic system may also pass through the lymphatic vessels of the meninges [18]. The transport of $\mathrm{A} \beta$ in the $\mathrm{BBB}$ is mediated by low-density lipoprotein receptor-related protein 1 (LRP1) [19], and the transport from brain tissue fluid to cerebrospinal fluid is through the glial lymphatic system, which is a network of perivascular space (PVS) and the foot processes of astrocytes surround PVS. There is clinical evidence that decreased cerebral blood flow increases the accumulation of $A \beta$ in the brain [20], especially $A \beta$ deposited in cerebral blood vessels may be one of the causes of inflammation and cytotoxic events, which can further cause BBB to be more extensive of leakage and destruction [21], see also Figure 1 for the transport and clearance of $A \beta$.

\subsection{Pathophysiological functions of $\alpha$-synuclein in PD}

PD is the second most prevalent neurodegenerative disease, next only to AD. Amongst the diagnostic of more than 10 million people diagnosed with PD worldwide, the major clinic lesions are degenerative dopaminergic neurons in substantia nigra. Among 55-60year-old populations, the incidence rate of PD is exponentially increased, imposing a heavy burden on the family and society [22]. The neurodegenerative disease is common in the aged, however, the onset of PD is not clear, in which risk factors are included but not limited to genetics, environment, as well as age. Unfortunately, no effective medications for the treatment of PD are available, where most of the current strategies are preventative medicine. Since the discovery of $\alpha$ Syn (PARK1) in the late 1990s, currently, there are 6 major causal risk genes (SNCA, PRKN, UCHL1, PARK7, LRRK2, PINK1) that are associated with familial PD [23]. However, only 5-10\% of patients with PD have a family medical history, where most of them are sporadic.

Under physiological conditions, $\alpha$ Syn is a soluble protein that mainly localizes on vesicles in pre-synapse. Current understanding of the functions of $\alpha$ Syn is still limited to vesicle trafficking, recycling, and secretion. Clinic autopsy of brains with PD revealed inclusions of Lewy bodies and Lewy neurites in the ventral tegmental area (VTA) and substantia nigra (SN). Later, researchers gradually recognized that the major component of Lewy bodies and Lewy neurites are phosphorylated and misfolded $\alpha$ Syn. In 1996, for the first time, the scientist observed the ultrastructure of Lewy body by electron microscopy [24]. Although the discovery of aSyn in PD was known to the public for decades, the mechanisms of its function, especially under pathological condition, remains largely unclear.

For many years, prion diseases were thought to be a unique group of neurodegenerative disorders in which the normal cellular prion protein $(\mathrm{PrPc})$ was conformationally altered by infectious prion protein PrPSc through 'seeded' fibrillization [25]. In recent decades, 
mounting evidence demonstrated that a prion-like self-propagating property may apply to a wide range of diseases with protein aggregation, including $\alpha$ Syn, tau, A $\beta$, huntingtin with ployQ repeats, superoxide dismutase 1 (SOD1), and TDP43. Pathological brain-derived lysates ( $\alpha$ Syn, tau, TDP43) were shown to act as templates or seeds that could efficiently recruit their soluble counterparts into insoluble fibrils in wild-type primary cultures, slice cultures, as well as in vivo [26-31]. Since human brains are valuable resources and are not available in every institute, people are seeking alternative options that could recruit pathological inclusions in wild-type tissues or in vivo.

About 10 years ago, recombinant $\alpha$ Syn monomers were reported to spontaneously aggregate into the preformed fibrils (PFFs) and induce $\alpha$ Syn inclusions in wild-type primary cultured hippocampal neurons and in vivo [28,32], as well as in slice cultures recently [33], which mimics the pathogenesis of PD in human brains. When self-template-dependent amplification for several rounds, these amyloidogenic PFF 'seeds' not only recruit endogenous $\alpha$ Syn but also recruit tau into aggregates both in vitro and in vivo [34]. In addition, under different salt conditions, these PFFs formed functionally and structurally different 'strains' with distinct neurotoxicity and biochemical properties [35]. As for deceased patients diagnosed with PD, the glial cytoplasmic inclusions (GCIs) extracted from the cerebellum are 1,000 times more potent than $\alpha$ Syn PFFs in inducing pathology and are 100 times more potent than Lewy body extracted from PD with dementia [36]. How and why the glial milieu modifies the $\beta$-sheet folding property of $\alpha$ Syn and contributes to its neuropathologic function opens for further investigation.

Considering the complexity and unpredictability of the structure of spontaneously formed $\alpha$ Syn PFFs, the potency of neurotoxicity varies from batches to batches, as this process was affected by salt, temperature as well as $\mathrm{pH}$ of the reaction system [35]. The biofluid samples (CSF and blood) from patients with AD and PD contain picogram levels of aggregated $\alpha$ Syn and tau, which can be used as template-dependent amplification seeds. One of the amplification techniques is the real-time quaking-induced conversion (RT-QuIC) assay, which can exponentially amplify a small amount of 'seeds' from various biopsies with high sensitivity and specificity, making it a useful tool to aid in the clinical diagnosis of neurodegenerative disorders [37]. RT-QuIC was first successful in the diagnosis of human prion disease and then applied to detect $\alpha$ Syn aggregates in the brain and CSF from dementia with Lewy body and PD patients [38]. In the latest study, a group of RT-QuIC reactions for $4 \mathrm{R}$ tauopathies has been developed, specifically PSP, CBD, and FTDP-17 MAPT [39]. This emerging template-dependent amplification technique would benefit the diagnosis of AD and PD far before the onset of clinical lesions, and investigate the underlying mechanism of the structural and functional diversities of distinct brainderived species is another challenging topic.

When adding PFFs into cultured hippocampal neurons, they compromised synaptic miniature EPSC firing frequency, inhibited spines formation, along with decreased action potential firing rate [40], where another group observed paradoxical functional defects induced by $\alpha$ Syn PFFs [41]. On the other hand, the neuronal hyperactivity promoted the secretion of $\alpha$ Syn into extracellular in vivo as well as in vitro [42], thus facilitated the propagation of pathology in CNS, and this was confirmed by an ex vivo slice culture system recently [33]. The activity-dependent regulation of protein aggregation and spreading also applies to tau and A $\beta$ in AD animal models [43-44]. For example, in a microdialysis study, neuronal activity modulated the concentration of $A \beta$ and tau in the extracellular interstitial fluid of mouse brains [45]. By imaging the traffic of fluorescent tag labeled tau in axons within microfluidic chambers, enhancing neuronal activity increased the release of tau and facilitated tau transmission [46]. Furthermore, a study that used a chemogenetic approach to modulate neuronal activity demonstrated that hyperactivity leads to increase $\mathrm{A} \beta$ load and was reversed by inhibiting neuronal activity in a transgenic animal in vivo [47]. Even before the formation of extracellular plaques, neurons in the prefrontal cortex 
showed hyperactivity and contributed to the progression of pathology in vivo [48], and this phenomenon was confirmed by ex vivo live imaging of hippocampal slice cultures in the 5xFAD model as well [33].

\subsection{Cell-cell transmission of pathogenic "seeds"}

When zoom-in into the donor cells, the formation and amplification of pathological seeds initialize the transmission process. Both anterograde and retrograde transport of these proteins were observed, however, the $A \beta$ fibrils were shown to be transported ten times more efficiently than $\alpha$ Syn [49-51]. When released outside of the neurons, both tau and $\alpha$ Syn fibrils can be taken up via macropinocytosis, a form of endocytosis mediated by heparan sulfate proteoglycans (HSPGs) on the cell surface [52]. In another study, a pool of 352 complementary DNAs was expressed in SH-SY5Y cells and screened for $\alpha$ Syn-biotin PFF-binding candidates. This large-scale screening approach identified one of the top candidates, lymphocyte-activation gene 3 (LAG3), a transmembrane protein internalized via receptor-mediated endocytosis [53]. After taken up through the plasma membrane, the fibrils then traffic along the endo-lysosomal pathway, process, rupture, and release from the lysosome into the cytosol before recruiting endogenous monomeric counterparts into insoluble inclusions (Figure 1), see also [54-56]. Moreover, tunneling nanotube (TNT)mediated cell-cell transfer of pathological tau and $\alpha$ Syn seeds was observed in vitro recently [57-58]. However, whether TNTs connecting neurons are present in vivo remains unclear.

As for propagation and spreading of pathologies in vivo, the stereotypic progression of misfolded proteins in AD and PD follows a predictable pattern. Cross-sectional autopsy studies indicate that $\beta$-amyloid plaques first appear in the neocortex, followed by the allocortex and finally subcortical regions [59]. Neurofibrillary tangles occur first in the locus coeruleus and transentorhinal area and then spread to the amygdala and interconnected neocortical brain regions [60]. Where propagation of Lewy body/Lewy neurite in patients with PD is postulated to start in the brainstem and ascend toward neocortical regions with disease progression [61]. The transmission of pathological tau and $\alpha$ Syn can occur bi-directionally within a network of interconnected populations, where the expression level of $\alpha$ Syn contributes to the selective vulnerability of hippocampal neuron subpopulations to fibrils-induced neurotoxicity [62].

\subsection{The application of RNA sequencing in understanding neuropathologies}

Since the development of Tang's single-cell RNA sequencing (scRNA-seq) method to understand the genomic transcriptome of mammalian cells in 2009 [63], this technique is booming as one of the most popular tools in the past decade. Previous scRNA-seq approaches from dissociated tissues use protease treatment at $30^{\circ} \mathrm{C}$, which is known to alter the transcriptome. For neuroscience research, the brain is a complicated mixture of neurons, glial and endothelial cells, and neurons are highly polarized structures, making it hard to isolate the whole RNAs with traditional processes. Thus, with the development of the single nuclear RNA-seq (snRNA-seq) method, nuclei can be isolated at $4{ }^{\circ} \mathrm{C}$ from tissue homogenates, which minimizes damage. Additionally, single nuclear transcriptomes can be obtained from postmortem human brain tissue stored at $-80^{\circ} \mathrm{C}$, making it possible to access the brain's genetic 'secrets' by RNA-seq via individual neurons. Here, we reviewed some of the recent progress of this emerging technology in the application of neurodegenerative diseases, and the latest spatial-temporal RNA-seq will also be discussed.

In 2016, Poulin et al. summarized the quantitative analysis of markers in a single cell, enabling the classification of neural cells into categories [64]. With the understanding of molecular diversities of neurons via scRNA-seq, it's getting closer to mapping the whole 
brain connectome at a single cell level. This will be an extremely important reference tool in the study of the nervous system and making unprecedented contributions to the field of neuroscience. Besides using it as the molecular classification tool, scRNA-seq has been largely applied in understanding mechanisms of diseases. By using microfluidic dynamic array-based scRNA-seq to simultaneously evaluate the expression of 96 genes in single neurons, Poulin et al. identified multiple novel subtypes of dopaminergic (DA) neurons which were localized in a distinct area of adult mouse brains. For example, Aldh1a1+ subtype DA neurons, located in the substantia nigra, are especially vulnerable in the 1-methyl-4-phenyl-1,2,3,6-tetrahydropyridine (MPTP) model of PD [65].

The dysfunction of the striatum is associated with multiple neurodegenerative and cognitive diseases, including PD, hypersomnia, schizophrenia as well as addiction [66]. According to the expression of D1 or D2 dopamine receptors, GABAnergic medium spiny neurons (MSNs) can be divided into D1 and D2 subtypes [67]. By using SMART-seq2 of 1208 cells isolated from mouse striatum, the authors found that D1 and D2 MSNs can be further classified into subgroups. In addition, they also identified cell type-specific transcription and splicing factors, and these factors can change cell types by modulating transcription and gene expression profiles [68]. As a substantial neurotransmitter, dopamine plays an essential role in neurodegeneration and cognitive diseases [69-70], thus, study the function of different types of dopaminergic neurons helps to understand the molecular basics and mechanisms of these diseases.

By analyzing single-cell transcriptomes of the GBA-N370S-PD iPSC-derived dopaminergic neurons, Lang et al. found a progression axis in response to endoplasmic reticulum (ER) stress. When analyzing differentially expressed genes (DEGs), the transcription inhibitor HDAC4 is upregulated during PD progression. In iPSC of PD patient-derived DA neurons, HDAC4, mainly localizes in the nuclear, inhibits gene expression during early progress of disease and results in defects of protein homeostasis in late-stage [71]. In 2017, Ido Amit's group discovered a new type of immune cells in the brain, disease-associated microglia (DAM), and proved that DAM is responsible to degrade dead cells and ADrelated amyloid plaques. DAM is a conservative phagocytic cell in humans and mice, whose activation is dependent or independent on TREM2 [72]. The author emphasized that, only by performing scRNA-seq they can find these infrequent microglia, providing new strategies to treat $\mathrm{AD}$ and related disorders.

scRNA-seq has a high demand on the cell suspension viability and numbers prepared from organs or solid tissues, which means many frozen precious clinical samples (brain tissue, tumor tissue) is not applicable for this method. Thus, the snRNA-seq is another option that, to some extent, overcame this problem. As for brain tissues, scRNA-seq cannot fully analyze all types of neurons as some neurons are more easily to be affected by the dissociation process. Although the tolerance of non-neuronal cells from the neocortex of human adults is better than neurons during dissociation, more non-neuronal cells are left in single nuclear suspension. As for the neocortex of mouse brains, the proportions of layer-5 parvalbumin-positive neurons and glutaminergic neurons are lower than expected. In contrast, nuclear is more resistant to mechanical treatment and can be dissociated from frozen tissues. Single nuclear has been proofed to cover enough gene expression messages to define cell types of humans and the hippocampus of the mouse.

Previous research reported that single nuclear was isolated from frozen S1 cortex, followed with sorting with NeuN antigen, and then RNA sequenced with Fluidigm C1 system. Gene numbers and subtypes are comparable between nuclear and cells, with an average of 5,619 genes in S1 nuclear and an average of 4,797 genes in S1 cells, where nuclear has higher proportions of intron reads [73]. Grubman et. al performed snRNA-seq of entorhinal cortex from deceased patients with Alzheimer's disease and age-matched healthy controls and got 13,214 nuclear, with a median of 646 genes per cell [74]. With AD autopsy cases, Mathys et. al performed snRNA-seq of frozen human tissues and identified major 
types of cells in the brain: excitatory neurons (NRGN+), inhibitory neuron (GAD1+), astrocyte $(\mathrm{AQP} 4+)$, oligodendrocyte (MBP), microglia (CSF1 and CD74+), oligodendrocyte progenitor cells (VCAN+), endothelial cells and pericytes (AMBP+) [75].

\subsection{Broad applications of the snRNA-seq technique in other systems}

snRNA-seq has been useful in heart tissues. The adult heat tissue cannot digest without damage of cells, making it not ideal for scRNA-seq; the size of a cardiomyocyte is relatively big, and the shape is not regularly round, making it hard to capture a single cell. So, previous research focused only on the heart from embryonic and newborn pups or noncardiomyocyte cells of the adult mouse. In 2020, a paper of mammalian snRNA-seq of heart tissue reported the cellular components and characteristics, which removed the obstacles of scRNA sequencing in the heart. From snRNA-seq analysis, there are 8,635 nuclear and 22,568 genes in the heart, with 2662.6 reads per cell. UMAP revealed 24 distinct cell types, endothelial (28.8\%) cells, fibroblasts (25.3\%) and cardiomyocytes $(22.8 \%)$ are among the top subtypes, which contain 2,500, 2,200 and 2,000 nuclear accordingly [76]. By using snRNA-seq, Cui et al. mapped the dynamic transcriptional landscape of five distinct cardiomyocyte populations in healthy, injured, and regenerating mouse hearts. More importantly, they identified immature cardiomyocytes that enter the cell cycle following injury which makes a breakthrough as the heart loses the ability to regenerate. The nuclear transcription factor Y subunit alpha (NFYa) and nuclear factor erythroid 2-like 1 (NFE2L1) were identified as proliferative and protective function, respectively, in this injury response process [77].

In addition, snRNA-seq is also applicable in renal tissue. Benjamin Humphreys from Washington University analyzed both scRNA-seq and snRNA-seq data from renal tissues. When compared with scRNA-seq, snRNA-seq captured more renal cells that were missed in scRNA-seq, such as the glomerular podocytes, mesangial cells as well as endothelial cells, and no detection of stress response genes. Also, snRNA-seq generated more than 20 times more podocytes when compared with published scRNA-seq database (2.4\% vs $0.12 \%$ ) [78-79]. Wilson et al. performed snRNA-seq of frozen tissues from diabetic nephropathy and got 23,980 nuclear in total, including 11 renal cell subtypes and 4 immune cell subtypes [80]. When incorporated with snATAC seq, Miao et al. identified broad changes of open chromatin and gene expression during nephron progenitor differentiation[81].

Overall, snRNA-seq is more universally applicable than scRNA-seq, it does not limit to fresh tissue, but also frozen ones. Additionally, a single nuclear is easier to prepare than a single cell as it needs less enzyme digestion, which results in less mechanical stressinduced pseudo cell subtypes. Regarding data analysis, snRNA-seq contains information of introns and intergenic regions, making the resolution of cellular subtypes higher. Can snRNA-seq replace scRNA-seq? The answer is NO! Choosing what kind of RNA-seq methods largely depends on the experimental conditions. What samples you have? Are they able to prepare qualified cell suspensions? Are they sensitive to enzymes? All these factors need to be considered. The combination uses of both scRNA-seq and snRNA-seq would be the ideal strategy to get full access to genome transcriptions.

The scRNA-seq technologies have enabled the use of single-cell transcriptional profiling to explore cellular heterogeneity. However, a common feature of scRNA-seq studies is that they do not resolve the spatial patterns or positional information, making it difficult to place cell-cell interactions within a broader tissue context. Harnessing in situ sequencing and quantitative analysis, the spatial transcriptomics (ST) refined these results and created a spatial subcellular map of 3D transcriptome profiles [82-83]. In 2019, Asp et al. collected human embryonic heart tissue at different development stages $(4.5-5,6.5$, and 9 post-conception weeks) and systematically analyzed subcellular resolution of regional 
markers and cell atlas based on ST and scRNA-seq [84]. As AD mouse model, Chen et al. investigated the ST of $100 \mu \mathrm{m}$ diameter around amyloid plaques and discovered early response genes that are enriched in myelin and oligodendrocytes, where plaque-induced genes (PIGs) involving the complement system, oxidative stress, lysosomes, and inflammation are prominent in the later phase of the disease [85]. To improve spatial resolution, Slide-seq [86] and HDST [87] were developed, in which they used an alternative strategy with condensed beads-based technology, making it feasible to profile genome-wide molecular events at the single-cell level.

\subsection{Conclusions}

The accumulation of $\alpha$ Syn aggregates in Parkinson's and related diseases is unstoppable, and preclinical symptoms can occur about 10-20 years before the lesions of neuronal functions. Though people have developed multiple strategies to predict, investigate and slow down the process, the progression is far behind expected. Biochemistry, molecular biology, autopsy, electron microscopy, and live imaging techniques enable us to learn the underlying mechanism of protein aggregation and spreading between neurons, however, all these traditional assays are biased focused on one or two genes at a time and neglect the complexity and integrity of the biological system. In the last decade, the booming of scRNA-seq and snRNA-seq techniques lead us into a 'big data' era that tens of thousands of genes and signal pathways have been uncovered within the same tissues. These big data also bring us too much 'noise' and it should be more careful to choose what kind of pathways or genes that fit your hypothesis in the future. And how to use the published database to explore useful information is another recycling of resources, which, of course, will benefit and guide the preclinical research.

\subsection{Figures}

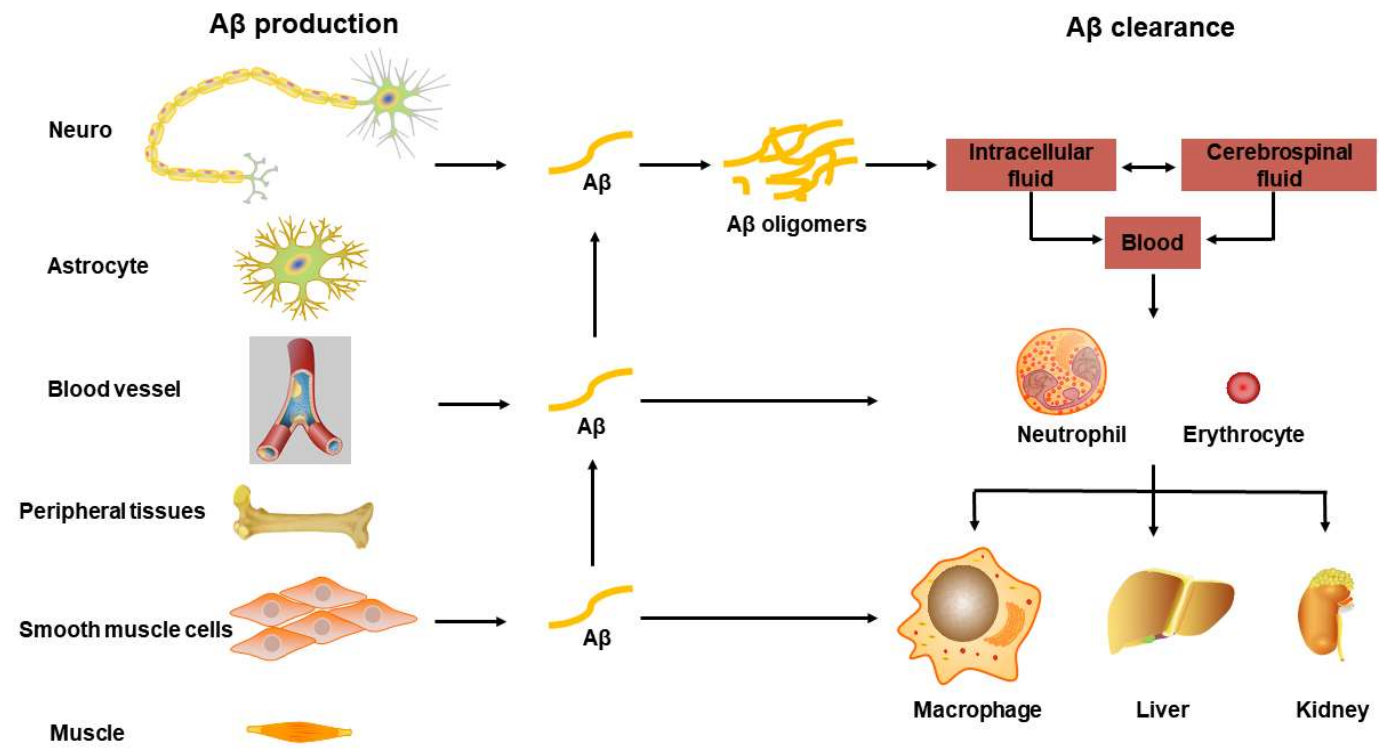

Figure 1: Transport and clearance of $A \beta$ in brain and peripheral tissues and organs.

$\mathrm{A} \beta$ is produced by neurons and glial cells in the brain, as well as peripheral blood vessel wall cells, skeletal muscle, and osteoblasts, etc., and secreted out of the cell; $A \beta$ in the central nervous system is transported through brain tissue fluid, cerebrospinal fluid, and blood-brain barrier In the peripheral blood; monocytes and neutrophils swallow part of $A \beta$, some are degraded by A $\beta$ degrading enzymes, and the other part is swallowed by macrophages in peripheral organs and tissues, or is excreted through bile and urine. 


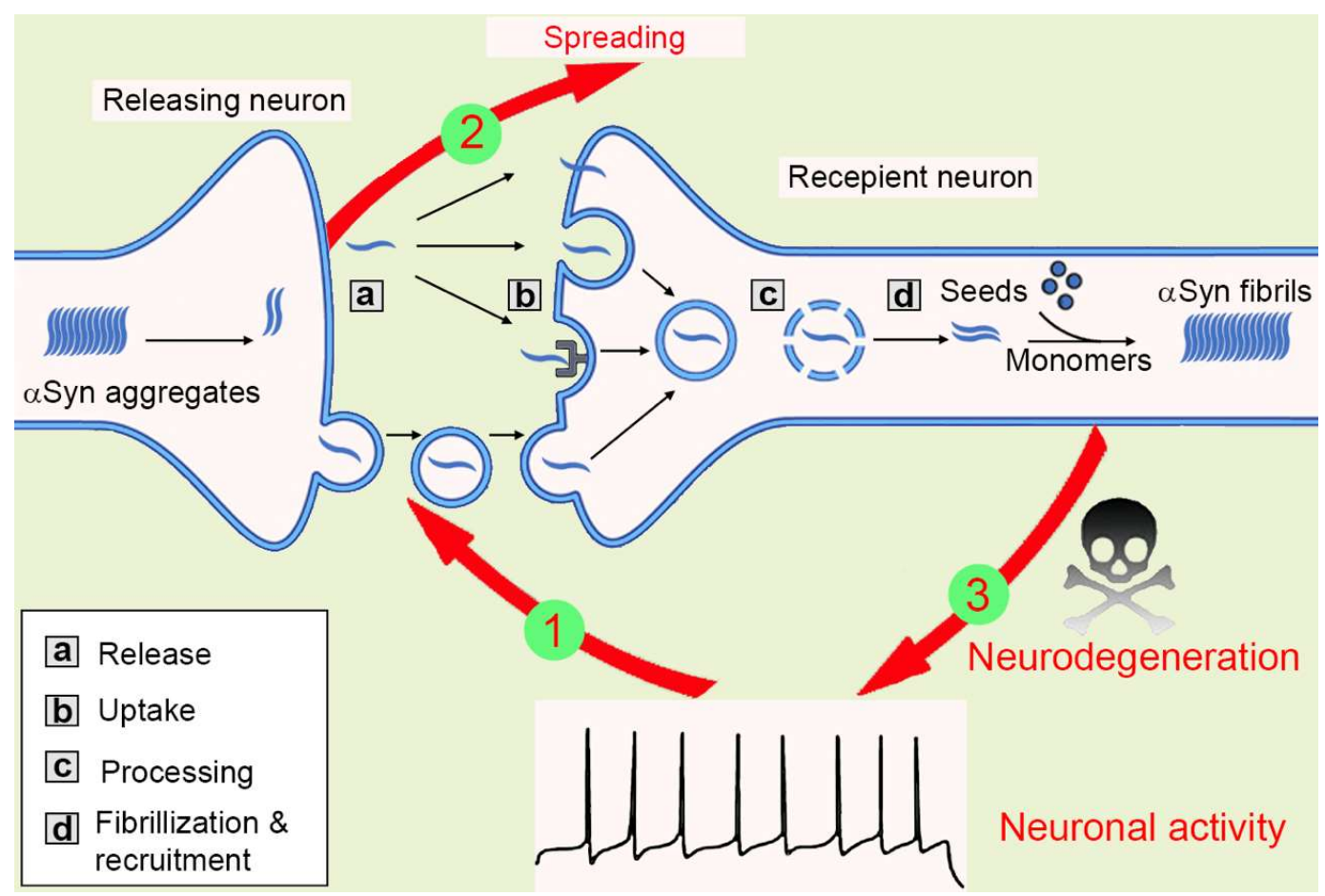

Figure 2: The spreading of $\alpha$ Syn aggregates between neurons.

Mutations or neurotoxic environmental factors initialize the $\alpha$ Syn aggregation in the releasing neuron. The aggregates are released into extracellular via vesicle/exosome, and neuronal activity facilitates or inhibits this process (1). Then, the aggregates are taken up by macropinocytosis, LAG-3 receptor, or penetration into cell membrane directly. The aggregates transport inside the recipient cells, most of them will be degraded in lysosome, but some lysosomes will be ruptured and release aggregates, that are working as 'seeds' to recruit endogenous $\alpha$ Syn monomers into new fibrils. Thus, the amyloidogenic aggregates spread between cells (2). The $\alpha$ Syn aggregates then compromise synaptic activity, inhibit spine formation, and finally result in neurodegeneration (3).

Author Contributions: Conceptualization, J.J. and Q.W.; methodology, J.J., Y.L.; validation, J.J., Y.L. and Q.W.; formal analysis, J.J.; investigation, J.J.; resources, J.J., Y.L.; data curation, J.J.; writingoriginal draft preparation, J.J.; writing - review and editing, Q.W.; visualization, Q.W.; supervision, Q.W.; project administration, Q.W.; funding acquisition, Q.W. All authors have read and agreed to the published version of the manuscript.

Funding: This research was funded by the Fundamental Research Funds for the Central Universities (22120210192, 22120210368), Shanghai Pujiang Program (21PJ1412100), National Natural Science Foundation of China (8210051511).

Acknowledgments: We thank Dr. Yuting Guan for reading of our manuscript.

Conflicts of Interest: The authors declare no conflict of interest.

\section{References}

1. Tokuchi R, Hishikawa N, Sato K, et al. Differences between the behavioral and psychological symptoms of Alzheimer' s disease and Parkinson's disease [J]. J Neural Sci, 2016,369:278-282. DOI:10. 1016/j. jns. 2016. 08. 053.

2. Perl DP. Neuropathology of Alzheimer's disease. Mt Sinai J Med. 2010 Jan-Feb;77(1):32-42. doi: 10.1002/msj.20157. 
3. Rabinovici GD, Karlawish J, Knopman D, et al. Testing and disclosures related to amyloid imaging and Alzheimer's disease: Common questions and fact sheet summary[J]. AlzheimersDement, 2016, 12(4):510-515.DDI:10. 1016/j. jalz. 2016. 03. 002.

4. Selkoe DJ, Hardy J. The amyloid hypothesis of Alzheimer' s disease at 25 years[J]. EMBO Mol Med, 2016, 8(6):595608. DOI:10. 15252/emmm. 201606210.

5. Sharma S, Verma S, Kapoor M, et al. Alzheimer' s disease like pathology induced six weeks after aggregated amyloidbeta injection in rats: increased oxidative stress and impaired long-term memory with anxiety-like behavior [J]. Neurol Res, 2016, 38 ( 9 ) :838-850. DOI:10. 1080/01616412. 2016.1209337.

6. Goedert M. Neurodegeneration. Alzheimer' s and Parkinson's diseases: The prion concept in relation to assembled A $\beta$, tau, and a-synuclein [J]. Science, 2015, 349(6248):1255555. DOI:10. 1126/science. 1255555.

7. Pooler AM, Polydoro M, Maury EA, et al. Amyloid acceler-ates tau propagation and toxicity in a model of early Alzheimer' s disease [J]. Acta Neuropathol Commun, 2015, 3:14. DOI:10. 1186/x40478-015-0199-x.

8. Minjarez B, Rustarazo ML, et al. Identification of proteins that are differentially expressed in brains with Alzheimer's disease using iTRAQ labeling and tandem mass spectrometry [J]. J Proteomics, 2016, 139:103-121. DOI:10. 1016/j. jprot. 2016. 03.022 .

9. Tycko R. Alzheimer's disease: Structure of aggregates revealed [J]. Nature, 2016, 537(7621) :492-493. DOI:10. 1038/nature19470.

10. Walsh DM, Klyubin I, Fadeeva JV, et al. Naturally secreted oligomers of amyloid beta protein potently inhibit hippocampal long-term potentiation in vivo [J]. Nature, 2002,416(6880):535-539. DOI:10. 1038/416535a.

11. Cleary JP, Walsh DM, Hofmeister JJ, et al. Natural oligomers of the amyloid-beta protein specifically disrupt cognifive function [J]. Nat Neurosci, 2005, 8(1):79-84.DOI:10.1038 /nn1372.

12. Grutzendler J, Helmin K, Tsai J, et al. Various dendritic abnormalities are associated with fibrillar amyloid deposits in Alzheimer' s disease [J]. Ann N Y Acad Sci, 2010, 1097(1):30-39. DOI:10. 1196/annals. 1379. 003.

13. Tsai J, Grutzendler J, Duff K, et al. Fibrillar amyloid deposition leads to local synaptic abnormalities and breakage of neuronal branches [J]. Nat Neurosci, 2004, 7(11):1181-

1183. DOI:10. 1038/nn1335.

14. Shankar GM, Li S, Mehta TH, et al. Amyloid-[beta ] protein dimers isolated directly from Alzheimer's brains impair synaptic plasticity and memory [J]. Nat Med, 2008, 14(8):837-842. DOI: 10. 1038/nm1782.

15. Shin MK, Kim HG, Kim KL. A novel brain-derived neurotrophic factnr-modulating peptide attenuates A $\beta 1-42$-induced neurotoxicity in vitro [J]. Neurosci Lett, 2015, 595:63-68. DOI:10. 1016/j. neulet. 2015. 03. 070.

16. Shi Q, Chowdhury S, Ma R, et al. Complement C3 deficiency protects against neurodegenera-tion in aged plaque-rich APP/PS1 mice [J]. Sci Transl Med, 2017, 9(392).DOI:10. 1126/scitranslmed. aaf6295.

17. Bachhuber T, Katzmarski N, Mccarter JF, et al. Inhibition of amyloid- $\beta$ plaque formation by a-synuclein [J]. Nat Med, 2015, 21(7):802-807. DOI:10. 1038/nm 3885.

18. Xiang Y, Bu XL, Liu YH, et al. Physiological amyloid-beta clearance in the periphery and its therapeutic potential for Alzheimer's disease [J]. Acta Neuropathol, 2015, 130 (4):487-499. DOI:10. 1007/s00401-015-1477-1.

19. Pflanzner T, Janko MC, Andre-Dohmen B, et al. LRPI mediates bidirectional transcytosis of amyloid-beta across the blood-brain barrier [J]. Neurobiol Aging, 2011, 32(12):2323. e1-e11. DOI:10. 1016/j. neurobiolaging. 2010. 05.025.

20. Mattsson N, Tosun D, Insel PS, et al. Association of brain amyloid-beta with cerebral perfusion and structure in Alzheimer' s disease and mild cognitive impairment [J]. Brain, 2014, 137(Pt 5):1550-1561. DOI:10. 1093/brain/awu043. 
21. Zenaro E, Piacentino G, Constantin G. The blood-brain barrier in Alzheimer's disease [J]. Neurobiol Dis, 2017, 107(1):41-56. DOI:10. 1016/j. nbd. 2016. 07. 007.

22. Baiano, C.; Barone, P.; Trojano, L.; Santangelo, G., Prevalence and clinical aspects of mild cognitive impairment in Parkinson's disease: A meta-analysis. Mov Disord 2020, 35, (1), 45-54.

23. Blauwendraat, C.; Nalls, M. A.; Singleton, A. B., The genetic architecture of Parkinson's disease. Lancet Neurol 2020, $19,(2), 170-178$.

24. Forno, L. S.; DeLanney, L. E.; Irwin, I.; Langston, J. W., Electron microscopy of Lewy bodies in the amygdalaparahippocampal region. Comparison with inclusion bodies in the MPTP-treated squirrel monkey. Advances in neurology 1996, 69, 217-28.

25. Aguzzi, A.; Sigurdson, C.; Heikenwaelder, M., Molecular mechanisms of prion pathogenesis. Annual review of pathology 2008, 3, 11-40.

26. Stohr, J.; Watts, J. C.; Mensinger, Z. L.; Oehler, A.; Grillo, S. K.; DeArmond, S. J.; Prusiner, S. B.; Giles, K., Purified and synthetic Alzheimer's amyloid beta (Abeta) prions. Proceedings of the National Academy of Sciences of the United States of America 2012, 109, (27), 11025-30.

27. Iba, M.; Guo, J. L.; McBride, J. D.; Zhang, B.; Trojanowski, J. Q.; Lee, V. M., Synthetic tau fibrils mediate transmission of neurofibrillary tangles in a transgenic mouse model of Alzheimer's-like tauopathy. The Journal of neuroscience : the official journal of the Society for Neuroscience 2013, 33, (3), 1024-37.

28. Volpicelli-Daley, L. A.; Luk, K. C.; Patel, T. P.; Tanik, S. A.; Riddle, D. M.; Stieber, A.; Meaney, D. F.; Trojanowski, J. Q.; Lee, V. M., Exogenous alpha-synuclein fibrils induce Lewy body pathology leading to synaptic dysfunction and neuron death. Neuron 2011, 72, (1), 57-71.

29. Chen, A. K.; Lin, R. Y.; Hsieh, E. Z.; Tu, P. H.; Chen, R. P.; Liao, T. Y.; Chen, W.; Wang, C. H.; Huang, J. J., Induction of amyloid fibrils by the C-terminal fragments of TDP-43 in amyotrophic lateral sclerosis. Journal of the American Chemical Society 2010, 132, (4), 1186-7.

30. Ren, P. H.; Lauckner, J. E.; Kachirskaia, I.; Heuser, J. E.; Melki, R.; Kopito, R. R., Cytoplasmic penetration and persistent infection of mammalian cells by polyglutamine aggregates. Nature cell biology 2009, 11, (2), 219-25.

31. Munch, C.; O'Brien, J.; Bertolotti, A., Prion-like propagation of mutant superoxide dismutase-1 misfolding in neuronal cells. Proceedings of the National Academy of Sciences of the United States of America 2011, 108, (9), 3548-53.

32. Luk, K. C.; Kehm, V.; Carroll, J.; Zhang, B.; O'Brien, P.; Trojanowski, J. Q.; Lee, V. M., Pathological alpha-synuclein transmission initiates Parkinson-like neurodegeneration in nontransgenic mice. Science 2012, 338, (6109), 949-53.

33. Wu, Q.; Shaikh, M. A.; Meymand, E. S.; Zhang, B.; Luk, K. C.; Trojanowski, J. Q.; Lee, V. M., Neuronal activity modulates alpha-synuclein aggregation and spreading in organotypic brain slice cultures and in vivo. Acta neuropathologica 2020, 140, (6), 831-849.

34. Guo, J. L.; Covell, D. J.; Daniels, J. P.; Iba, M.; Stieber, A.; Zhang, B.; Riddle, D. M.; Kwong, L. K.; Xu, Y.; Trojanowski, J. Q.; Lee, V. M., Distinct alpha-synuclein strains differentially promote tau inclusions in neurons. Cell 2013, 154, (1), 103-17.

35. Patterson, J. R.; Polinski, N. K.; Duffy, M. F.; Kemp, C. J.; Luk, K. C.; Volpicelli-Daley, L. A.; Kanaan, N. M.; Sortwell, C. E., Generation of Alpha-Synuclein Preformed Fibrils from Monomers and Use In Vivo. Journal of visualized experiments : JoVE 2019, (148).

36. Peng, C.; Gathagan, R. J.; Covell, D. J.; Medellin, C.; Stieber, A.; Robinson, J. L.; Zhang, B.; Pitkin, R. M.; Olufemi, M. F.; Luk, K. C.; Trojanowski, J. Q.; Lee, V. M., Cellular milieu imparts distinct pathological alpha-synuclein strains in alpha-synucleinopathies. Nature 2018, 557, (7706), 558-563. 
37. Saijo, E.; Groveman, B. R.; Kraus, A.; Metrick, M.; Orru, C. D.; Hughson, A. G.; Caughey, B., Ultrasensitive RT-QuIC Seed Amplification Assays for Disease-Associated Tau, alpha-Synuclein, and Prion Aggregates. Methods in molecular biology 2019, 1873, 19-37.

38. Fairfoul, G.; McGuire, L. I.; Pal, S.; Ironside, J. W.; Neumann, J.; Christie, S.; Joachim, C.; Esiri, M.; Evetts, S. G.; Rolinski, M.; Baig, F.; Ruffmann, C.; Wade-Martins, R.; Hu, M. T.; Parkkinen, L.; Green, A. J., Alpha-synuclein RTQuIC in the CSF of patients with alpha-synucleinopathies. Annals of clinical and translational neurology 2016, 3, (10), 812-818.

39. Saijo, E.; Metrick, M. A., 2nd; Koga, S.; Parchi, P.; Litvan, I.; Spina, S.; Boxer, A.; Rojas, J. C.; Galasko, D.; Kraus, A.; Rossi, M.; Newell, K.; Zanusso, G.; Grinberg, L. T.; Seeley, W. W.; Ghetti, B.; Dickson, D. W.; Caughey, B., 4-Repeat tau seeds and templating subtypes as brain and CSF biomarkers of frontotemporal lobar degeneration. Acta neuropathologica 2020, 139, (1), 63-77.

40. Wu, Q.; Takano, H.; Riddle, D. M.; Trojanowski, J. Q.; Coulter, D. A.; Lee, V. M., alpha-Synuclein (alphaSyn) Preformed Fibrils Induce Endogenous alphaSyn Aggregation, Compromise Synaptic Activity and Enhance Synapse Loss in Cultured Excitatory Hippocampal Neurons. The Journal of neuroscience : the official journal of the Society for Neuroscience 2019, 39, (26), 5080-5094.

41. Froula, J. M.; Henderson, B. W.; Gonzalez, J. C.; Vaden, J. H.; McLean, J. W.; Wu, Y.; Banumurthy, G.; OverstreetWadiche, L.; Herskowitz, J. H.; Volpicelli-Daley, L. A., alpha-Synuclein fibril-induced paradoxical structural and functional defects in hippocampal neurons. Acta neuropathologica communications 2018, 6, (1), 35.

42. Yamada, K.; Iwatsubo, T., Extracellular alpha-synuclein levels are regulated by neuronal activity. Molecular neurodegeneration 2018, 13, (1), 9.

43. Wu, J. W.; Hussaini, S. A.; Bastille, I. M.; Rodriguez, G. A.; Mrejeru, A.; Rilett, K.; Sanders, D. W.; Cook, C.; Fu, H.; Boonen, R. A.; Herman, M.; Nahmani, E.; Emrani, S.; Figueroa, Y. H.; Diamond, M. I.; Clelland, C. L.; Wray, S.; Duff, K. E., Neuronal activity enhances tau propagation and tau pathology in vivo. Nature neuroscience 2016, 19, (8), 108592.

44. Bassil, F.; Meymand, E. S.; Brown, H. J.; Xu, H.; Cox, T. O.; Pattabhiraman, S.; Maghames, C. M.; Wu, Q.; Zhang, B.; Trojanowski, J. Q.; Lee, V. M., alpha-Synuclein modulates tau spreading in mouse brains. The Journal of experimental medicine 2021, 218, (1).

45. Bero, A. W.; Yan, P.; Roh, J. H.; Cirrito, J. R.; Stewart, F. R.; Raichle, M. E.; Lee, J. M.; Holtzman, D. M., Neuronal activity regulates the regional vulnerability to amyloid-beta deposition. Nature neuroscience 2011, 14, (6), 750-6.

46. Wang, Y.; Balaji, V.; Kaniyappan, S.; Kruger, L.; Irsen, S.; Tepper, K.; Chandupatla, R.; Maetzler, W.; Schneider, A.; Mandelkow, E.; Mandelkow, E. M., The release and trans-synaptic transmission of Tau via exosomes. Molecular neurodegeneration 2017, 12, (1), 5.

47. Yuan, P.; Grutzendler, J., Attenuation of beta-Amyloid Deposition and Neurotoxicity by Chemogenetic Modulation of Neural Activity. The Journal of neuroscience : the official journal of the Society for Neuroscience 2016, 36, (2), 632-41.

48. Zott, B.; Simon, M. M.; Hong, W.; Unger, F.; Chen-Engerer, H. J.; Frosch, M. P.; Sakmann, B.; Walsh, D. M.; Konnerth, A., A vicious cycle of beta amyloid-dependent neuronal hyperactivation. Science 2019, 365, (6453), 559-565.

49. Wu, J. W.; Herman, M.; Liu, L.; Simoes, S.; Acker, C. M.; Figueroa, H.; Steinberg, J. I.; Margittai, M.; Kayed, R.; Zurzolo, C.; Di Paolo, G.; Duff, K. E., Small misfolded Tau species are internalized via bulk endocytosis and anterogradely and retrogradely transported in neurons. The Journal of biological chemistry 2013, 288, (3), $1856-70$.

50. Brahic, M.; Bousset, L.; Bieri, G.; Melki, R.; Gitler, A. D., Axonal transport and secretion of fibrillar forms of alphasynuclein, Abeta42 peptide and HTTExon 1. Acta neuropathologica 2016, 131, (4), 539-48. 
51. Freundt, E. C.; Maynard, N.; Clancy, E. K.; Roy, S.; Bousset, L.; Sourigues, Y.; Covert, M.; Melki, R.; Kirkegaard, K.; Brahic, M., Neuron-to-neuron transmission of alpha-synuclein fibrils through axonal transport. Annals of neurology 2012, 72, (4), 517-24.

52. Holmes, B. B.; DeVos, S. L.; Kfoury, N.; Li, M.; Jacks, R.; Yanamandra, K.; Ouidja, M. O.; Brodsky, F. M.; Marasa, J.; Bagchi, D. P.; Kotzbauer, P. T.; Miller, T. M.; Papy-Garcia, D.; Diamond, M. I., Heparan sulfate proteoglycans mediate internalization and propagation of specific proteopathic seeds. Proceedings of the National Academy of Sciences of the United States of America 2013, 110, (33), E3138-47.

53. Mao, X.; Ou, M. T.; Karuppagounder, S. S.; Kam, T. I.; Yin, X.; Xiong, Y.; Ge, P.; Umanah, G. E.; Brahmachari, S.; Shin, J. H.; Kang, H. C.; Zhang, J.; Xu, J.; Chen, R.; Park, H.; Andrabi, S. A.; Kang, S. U.; Goncalves, R. A.; Liang, Y.; Zhang, S.; Qi, C.; Lam, S.; Keiler, J. A.; Tyson, J.; Kim, D.; Panicker, N.; Yun, S. P.; Workman, C. J.; Vignali, D. A.; Dawson, V. L.; Ko, H. S.; Dawson, T. M., Pathological alpha-synuclein transmission initiated by binding lymphocyteactivation gene 3. Science 2016, 353, (6307).

54. Karpowicz, R. J., Jr.; Haney, C. M.; Mihaila, T. S.; Sandler, R. M.; Petersson, E. J.; Lee, V. M., Selective imaging of internalized proteopathic alpha-synuclein seeds in primary neurons reveals mechanistic insight into transmission of synucleinopathies. The Journal of biological chemistry 2017, 292, (32), 13482-13497.

55. Oueslati, A.; Ximerakis, M.; Vekrellis, K., Protein Transmission, Seeding and Degradation: Key Steps for alphaSynuclein Prion-Like Propagation. Experimental neurobiology 2014, 23, (4), 324-36.

56. Guo, J. L.; Lee, V. M., Cell-to-cell transmission of pathogenic proteins in neurodegenerative diseases. Nature medicine 2014, 20, (2), 130-8.

57. Tardivel, M.; Begard, S.; Bousset, L.; Dujardin, S.; Coens, A.; Melki, R.; Buee, L.; Colin, M., Tunneling nanotube (TNT)-mediated neuron-to neuron transfer of pathological Tau protein assemblies. Acta neuropathologica communications 2016, 4, (1), 117.

58. Abounit, S.; Bousset, L.; Loria, F.; Zhu, S.; de Chaumont, F.; Pieri, L.; Olivo-Marin, J. C.; Melki, R.; Zurzolo, C., Tunneling nanotubes spread fibrillar alpha-synuclein by intercellular trafficking of lysosomes. The EMBO journal 2016, $35,(19), 2120-2138$.

59. Thal, D. R.; Rub, U.; Orantes, M.; Braak, H., Phases of A beta-deposition in the human brain and its relevance for the development of AD. Neurology 2002, 58, (12), 1791-800.

60. Braak, H.; Del Tredici, K., The pathological process underlying Alzheimer's disease in individuals under thirty. Acta neuropathologica 2011, 121, (2), 171-81.

61. Braak, H.; Del Tredici, K.; Rub, U.; de Vos, R. A.; Jansen Steur, E. N.; Braak, E., Staging of brain pathology related to sporadic Parkinson's disease. Neurobiology of aging 2003, 24, (2), 197-211.

62. Luna, E.; Decker, S. C.; Riddle, D. M.; Caputo, A.; Zhang, B.; Cole, T.; Caswell, C.; Xie, S. X.; Lee, V. M. Y.; Luk, K. C., Differential alpha-synuclein expression contributes to selective vulnerability of hippocampal neuron subpopulations to fibril-induced toxicity. Acta neuropathologica 2018, 135, (6), 855-875.

63. Tang, F.; Barbacioru, C.; Wang, Y.; Nordman, E.; Lee, C.; Xu, N.; Wang, X.; Bodeau, J.; Tuch, B. B.; Siddiqui, A.; Lao, K.; Surani, M. A., mRNA-Seq whole-transcriptome analysis of a single cell. Nature methods 2009, 6, (5), $377-82$.

64. Poulin, J. F.; Tasic, B.; Hjerling-Leffler, J.; Trimarchi, J. M.; Awatramani, R., Disentangling neural cell diversity using single-cell transcriptomics. Nature neuroscience 2016, 19, (9), 1131-41.

65. Poulin, J. F.; Zou, J.; Drouin-Ouellet, J.; Kim, K. Y.; Cicchetti, F.; Awatramani, R. B., Defining midbrain dopaminergic neuron diversity by single-cell gene expression profiling. Cell reports 2014, 9, (3), 930-43.

66. De Deurwaerdere, P.; Di Giovanni, G.; Millan, M. J., Expanding the repertoire of L-DOPA's actions: A comprehensive review of its functional neurochemistry. Progress in neurobiology 2017, 151, 57-100. 
67. Surmeier, D. J.; Ding, J.; Day, M.; Wang, Z.; Shen, W., D1 and D2 dopamine-receptor modulation of striatal glutamatergic signaling in striatal medium spiny neurons. Trends in neurosciences 2007, 30, (5), 228-35.

68. Gokce, O.; Stanley, G. M.; Treutlein, B.; Neff, N. F.; Camp, J. G.; Malenka, R. C.; Rothwell, P. E.; Fuccillo, M. V.; Sudhof, T. C.; Quake, S. R., Cellular Taxonomy of the Mouse Striatum as Revealed by Single-Cell RNA-Seq. Cell reports 2016, 16, (4), 1126-1137.

69. Caudle, W. M.; Richardson, J. R.; Wang, M. Z.; Taylor, T. N.; Guillot, T. S.; McCormack, A. L.; Colebrooke, R. E.; Di Monte, D. A.; Emson, P. C.; Miller, G. W., Reduced vesicular storage of dopamine causes progressive nigrostriatal neurodegeneration. The Journal of neuroscience : the official journal of the Society for Neuroscience 2007, 27, (30), $8138-48$.

70. Chen, L.; Ding, Y.; Cagniard, B.; Van Laar, A. D.; Mortimer, A.; Chi, W.; Hastings, T. G.; Kang, U. J.; Zhuang, X., Unregulated cytosolic dopamine causes neurodegeneration associated with oxidative stress in mice. The Journal of neuroscience : the official journal of the Society for Neuroscience 2008, 28, (2), 425-33.

71. Lang, C.; Campbell, K. R.; Ryan, B. J.; Carling, P.; Attar, M.; Vowles, J.; Perestenko, O. V.; Bowden, R.; Baig, F.; Kasten, M.; Hu, M. T.; Cowley, S. A.; Webber, C.; Wade-Martins, R., Single-Cell Sequencing of iPSC-Dopamine Neurons Reconstructs Disease Progression and Identifies HDAC4 as a Regulator of Parkinson Cell Phenotypes. Cell stem cell 2019, 24, (1), 93-106 e6.

72. Keren-Shaul, H.; Spinrad, A.; Weiner, A.; Matcovitch-Natan, O.; Dvir-Szternfeld, R.; Ulland, T. K.; David, E.; Baruch, K.; Lara-Astaiso, D.; Toth, B.; Itzkovitz, S.; Colonna, M.; Schwartz, M.; Amit, I., A Unique Microglia Type Associated with Restricting Development of Alzheimer's Disease. Cell 2017, 169, (7), 1276-1290 e17.

73. Lake, B. B.; Chen, S.; Sos, B. C.; Fan, J.; Kaeser, G. E.; Yung, Y. C.; Duong, T. E.; Gao, D.; Chun, J.; Kharchenko, P. V.; Zhang, K., Integrative single-cell analysis of transcriptional and epigenetic states in the human adult brain. Nature biotechnology 2018, 36, (1), 70-80.

74. Grubman, A.; Chew, G.; Ouyang, J. F.; Sun, G.; Choo, X. Y.; McLean, C.; Simmons, R. K.; Buckberry, S.; VargasLandin, D. B.; Poppe, D.; Pflueger, J.; Lister, R.; Rackham, O. J. L.; Petretto, E.; Polo, J. M., A single-cell atlas of entorhinal cortex from individuals with Alzheimer's disease reveals cell-type-specific gene expression regulation. Nature neuroscience 2019, 22, (12), 2087-2097.

75. Mathys, H.; Davila-Velderrain, J.; Peng, Z.; Gao, F.; Mohammadi, S.; Young, J. Z.; Menon, M.; He, L.; Abdurrob, F.; Jiang, X.; Martorell, A. J.; Ransohoff, R. M.; Hafler, B. P.; Bennett, D. A.; Kellis, M.; Tsai, L. H., Single-cell transcriptomic analysis of Alzheimer's disease. Nature 2019, 570, (7761), 332-337.

76. Selewa, A.; Dohn, R.; Eckart, H.; Lozano, S.; Xie, B.; Gauchat, E.; Elorbany, R.; Rhodes, K.; Burnett, J.; Gilad, Y.; Pott, S.; Basu, A., Systematic Comparison of High-throughput Single-Cell and Single-Nucleus Transcriptomes during Cardiomyocyte Differentiation. Scientific reports 2020, 10, (1), 1535.

77. Cui, M.; Wang, Z.; Chen, K.; Shah, A. M.; Tan, W.; Duan, L.; Sanchez-Ortiz, E.; Li, H.; Xu, L.; Liu, N.; Bassel-Duby, R.; Olson, E. N., Dynamic Transcriptional Responses to Injury of Regenerative and Non-regenerative Cardiomyocytes Revealed by Single-Nucleus RNA Sequencing. Developmental cell 2020, 55, (5), 665-667.

78. Wu, H.; Kirita, Y.; Donnelly, E. L.; Humphreys, B. D., Advantages of Single-Nucleus over Single-Cell RNA Sequencing of Adult Kidney: Rare Cell Types and Novel Cell States Revealed in Fibrosis. Journal of the American Society of Nephrology : JASN 2019, 30, (1), 23-32.

79. Muto, Y.; Wilson, P. C.; Ledru, N.; Wu, H.; Dimke, H.; Waikar, S. S.; Humphreys, B. D., Single cell transcriptional and chromatin accessibility profiling redefine cellular heterogeneity in the adult human kidney. Nat Commun 2021, 12, (1), 2190. 
80. Wilson, P. C.; Wu, H.; Kirita, Y.; Uchimura, K.; Ledru, N.; Rennke, H. G.; Welling, P. A.; Waikar, S. S.; Humphreys, B. D., The single-cell transcriptomic landscape of early human diabetic nephropathy. Proceedings of the National Academy of Sciences of the United States of America 2019, 116, (39), 19619-19625.

81. Miao, Z.; Balzer, M. S.; Ma, Z.; Liu, H.; Wu, J.; Shrestha, R.; Aranyi, T.; Kwan, A.; Kondo, A.; Pontoglio, M.; Kim, J.; Li, M.; Kaestner, K. H.; Susztak, K., Single cell regulatory landscape of the mouse kidney highlights cellular differentiation programs and disease targets. Nat Commun 2021, 12, (1), 2277.

82. Stahl, P. L.; Salmen, F.; Vickovic, S.; Lundmark, A.; Navarro, J. F.; Magnusson, J.; Giacomello, S.; Asp, M.; Westholm, J. O.; Huss, M.; Mollbrink, A.; Linnarsson, S.; Codeluppi, S.; Borg, A.; Ponten, F.; Costea, P. I.; Sahlen, P.; Mulder, J.; Bergmann, O.; Lundeberg, J.; Frisen, J., Visualization and analysis of gene expression in tissue sections by spatial transcriptomics. Science 2016, 353, (6294), 78-82.

83. Salmen, F.; Stahl, P. L.; Mollbrink, A.; Navarro, J. F.; Vickovic, S.; Frisen, J.; Lundeberg, J., Barcoded solid-phase RNA capture for Spatial Transcriptomics profiling in mammalian tissue sections. Nature protocols 2018, 13, (11), $2501-2534$.

84. Asp, M.; Giacomello, S.; Larsson, L.; Wu, C.; Furth, D.; Qian, X.; Wardell, E.; Custodio, J.; Reimegard, J.; Salmen, F.; Osterholm, C.; Stahl, P. L.; Sundstrom, E.; Akesson, E.; Bergmann, O.; Bienko, M.; Mansson-Broberg, A.; Nilsson, M.; Sylven, C.; Lundeberg, J., A Spatiotemporal Organ-Wide Gene Expression and Cell Atlas of the Developing Human Heart. Cell 2019, 179, (7), 1647-1660 e19.

85. Chen, W. T.; Lu, A.; Craessaerts, K.; Pavie, B.; Sala Frigerio, C.; Corthout, N.; Qian, X.; Lalakova, J.; Kuhnemund, M.; Voytyuk, I.; Wolfs, L.; Mancuso, R.; Salta, E.; Balusu, S.; Snellinx, A.; Munck, S.; Jurek, A.; Fernandez Navarro, J.; Saido, T. C.; Huitinga, I.; Lundeberg, J.; Fiers, M.; De Strooper, B., Spatial Transcriptomics and In Situ Sequencing to Study Alzheimer's Disease. Cell 2020, 182, (4), 976-991 e19.

86. Rodriques, S. G.; Stickels, R. R.; Goeva, A.; Martin, C. A.; Murray, E.; Vanderburg, C. R.; Welch, J.; Chen, L. M.; Chen, F.; Macosko, E. Z., Slide-seq: A scalable technology for measuring genome-wide expression at high spatial resolution. Science 2019, 363, (6434), 1463-1467.

87. Vickovic, S.; Eraslan, G.; Salmen, F.; Klughammer, J.; Stenbeck, L.; Schapiro, D.; Aijo, T.; Bonneau, R.; Bergenstrahle, L.; Navarro, J. F.; Gould, J.; Griffin, G. K.; Borg, A.; Ronaghi, M.; Frisen, J.; Lundeberg, J.; Regev, A.; Stahl, P. L., High-definition spatial transcriptomics for in situ tissue profiling. Nature methods 2019, 16, (10), 987-990. 